\title{
Linhas de criação em uma aula de história: o paradoxo do pensamento diante do dispositivo de banalização
}

\author{
Caroline Pacievitch ${ }^{1}$ \\ ORCID: 0000-0003-3484-8168 \\ Nilton Mullet Pereira ${ }^{1}$ \\ ORCID: 0000-0002-2280-1920
}

\section{Resumo}

Esse artigo discute a aula de história como oportunidade para pensar e problematizar o tempo, a partir das criações dos docentes. Tal oportunidade se constrói na mediação com os jovens e suas culturas, com os conhecimentos históricos e com questões sensíveis. Em tempos em que a opinião comum parece assumir lugar de destaque, em que multiplicamse os ataques às aulas de história e em que se desenvolve um processo deliberado de desvalorização do pensamento e da produção científica, particularmente na área de história, nos propomos problematizar o que denominamos de dispositivo de banalização, com base nas ideias de Hannah Arendt e Michel Foucault. Nosso objetivo é refletir sobre a aula de história, tomando cenas de práticas de docência de estagiários e a literatura da área como fontes de pesquisa e de produção de conhecimento. Para este artigo, selecionamos uma aula que problematiza os imaginários que construímos sobre o Egito Antigo. A conexão que estabelecemos é que, enquanto o dispositivo de banalidade produz e reproduz olhares, leituras e relações na sociedade em geral, a sala de aula de história cria um refúgio para o pensamento ao abrir o espaço "entre" o passado e o futuro - lugar da imaginação que permite o reencontro criativo com os outros.

\section{Palavras-chave}

Ensino de história - Pensamento - Dispositivo de banalidade.

1- Universidade Federal do Rio Grande do Sul, Porto Alegre, RS, Brasil.

Contatos: pacievitch@gmail.com; niltonmp.pead@gmail.com 


\section{Creative lines in a history class: the paradox of thinking faced with the dispositif of banality}

\section{Abstract}

This article discusses history class as an opportunity to consider and problematize time, based on the creations of teachers. This opportunity is constructed in mediations with youth and their cultures, with historic knowledge and with sentient issues. In times when common public opinion appears to have an important position, when attacks on history classes multiply and when there is a deliberate process of devalorization of thinking and scientific production, particularly in the field of history, we propose to problematize what we call the dispositif of banalization, based on ideas from Hannah Arendt and Michel Foucault. Our objective is to reflect on history classes, using scenes of practices of student teachers and literature from the field as sources for research and producing knowledge. For this article we have selected a class that problematizes imaginaries constructed about Ancient Egypt. The connection that we establish is that, while the dispositif of banality produces and reproduces perspectives, readings and relations in society in general, the history classroom creates a refuge for thinking by opening a space "between" the past and future - a space of imagination that allows the creative re-encounter with others.

\section{Keywords}

Teaching history - thinking - Dispositif of banality.

Será possivel que o problema do bem e do mal, o problema de nossa faculdade para distinguir o que é certo do que é errado, esteja conectado com nossa faculdade de pensar?

Arendt, 2008, p. 19

\section{Introdução}

Recentemente temos nos ocupado em pensar sobre como o ensino e a aula de história podem se inserir num debate bastante delicado, que consiste em um processo de desvalorização das narrativas disciplinares e da própria produção científica em geral. Esse processo parece estar ligado a um efeito contrário, que é uma valorização excessiva da opinião comum, criando o que estamos denominando de um dispositivo da banalidade ${ }^{2}$. $\mathrm{Na}$ esteira desse movimento em torno da banalidade, nos propomos a pensar como as narrativas históricas ${ }^{3}$ e os saberes tradicionais (MEINERZ; GASPAROTTO, 2018) podem

2- 0 conceito de dispositivo de banalidade faz referência ao conceito que fez parte da produção literária e do pensamento de Michel Foucault.

3- Por narrativa histórica compreendemos o conhecimento histórico propriamente dito, criado no âmbito da pesquisa acadêmica e divulgado pelas publicações científicas. A ideia de narrativa na história foi problematizada por diversos teóricos, dentre eles, Paul Ricouer, na trilogia Tempo e Narrativa (2010). 
criar estratégias expressivas para dar a ver a historicidade e problematizar os discursos negacionistas (bem como os discursos de ódio) que constituem a materialidade do banal e que têm habitado tanto a sociedade em geral quanto a própria sala de aula.

Neste ensaio objetivamos realizar uma leitura antropofágica ${ }^{4}$ de dois conceitos: a banalidade do mal e o pensamento, a partir das concepções de Michel Foucault e Hannah Arendt (1999, 2009). 0 objetivo é colocar em xeque esse dispositivo de banalidade que tem se instituído, disseminado discursos e constituído subjetividades na sociedade brasileira e na aula de história. Nosso pressuposto é de que isso se dá a partir de processos de banalização e de recuo do pensamento, de tal forma que banalização e pensamento são considerados estranhos e contrapostos, incapazes de constituir, de uma só vez, um lugar de criação e de liberdade. Pretendemos dialogar com parte da literatura da área de ensino de história e com uma experiência produzida por estudantes estagiários da licenciatura em história da Universidade Federal do Rio Grande do Sul (UFRGS), que, em nosso entendimento, revolucionam o modo como os tempos e os clichês têm sido tratados em sala de aula, procurando formas de promover a aula de história como momento livre para a criação e para o diálogo.

\section{Sobre o dispositivo da banalidade, a banalidade do mal e o pensar}

Nunca é pouco ou fortuito lembrar Hannah Arendt (1999) e sua importante compreensão de como se constituem sociedades fascistas e governos totalitários. Quando a pensadora se propôs a realizar a cobertura, em 1961, do julgamento de Otto Adolf Eichmann, em Jerusalém, para a revista The New Yorker, a criação do conceito de banalidade do mal se tornou um modo de dar sentido a um processo que dificilmente faz qualquer sentido: o extermínio, o assassinato e a extirpação da vida do outro como atitudes banais, justificáveis, produzidas por uma cadeia de comando e por um respeito à hierarquia.

0 relato de todo o processo, sob a ótica da pensadora política, foi registrado no livro Eichmann em Jerusalém: um relato sobre a banalidade do mal, publicado em 1963. "Banalidade do mal" é, portanto, um conceito criado pela autora não exatamente para explicar ou criar uma teoria sobre o fenômeno, mas para produzir aí uma lição, a partir da postura, do comportamento e das palavras diante do tribunal, daquele que foi o responsável pela logística do envio de milhões de pessoas aos campos de concentração e de extermínio. Na compreensão da autora, a atitude de Eichmann era diferente.

Em primeiro lugar, a acusação de assassinato estava errada: "Com o assassinato dos judeus não tive nada a ver. Nunca matei um judeu, nem um não-judeu - nunca matei nenhum ser humano. Nunca dei uma ordem para matar fosse um judeu fosse um não-judeu; simplesmente não fiz isso", ou, conforme confirmaria depois: "Acontece [...] que nenhuma vez eu fiz isso" - pois não

4- A ideia de leitura antropofágica dos conceitos faz referência ao uso que Carla de Moura, em dissertação de mestrado defendida na UFRGS em 2018, no "Mestrado Profissional em Ensino de História", fez do termo antropofagia, ao revelar o uso de conceitos de pensadores europeus, em um trabalho que versou sobre a potencialidade do ensino de história intersecional em uma escola de periferia da cidade de Porto Alegre. 
deixou nenhuma dúvida de que teria matado o próprio pai se houvesse recebido ordem nesse sentido. (ARENDT, 1999, p. 17).

Para Arendt, Eichmann parecia não ter qualquer motivação para sua precípua missão, nem mesmo percebeu o que fazia como algo maligno. Eis o elemento mais terrificante da banalidade do mal: a falta de motivação e a falta de um sentimento de responsabilidade que conduza a uma ética e a uma política que obrigue a pensar. 0 mal, na ótica de Arendt, não consiste em um elemento do campo religioso ou mitológico, mas da ética e da política, ou das atividades de pensar, querer e julgar, de tal forma que se pode pensar em uma política do mal que conduza a uma racionalidade (BAUMAN, 1998) que produz a morte e a dizimação. A estrutura da máquina de morte do nazismo inseriu num ponto qualquer da engrenagem o personagem - Eichmann - e, a partir desse lugar, promoveu uma logística que consistia em enviar para a morte milhares de pessoas. Mas, afinal de contas, se há uma culpa para ser expiada, ela é da estrutura, da hierarquia, da necessidade da inexistência do outro, do apagamento do outro, de sua forma de vida - neste caso, nociva, conforme a ideologia do partido e do Estado. 0 elemento absolutamente incompreensível é justamente essa irresponsabilidade moral, que torna uma pessoa comum - que ama seus filhos, pratica a caridade, vai à igreja aos domingos - um assassino, incapaz de se culpabilizar e de pensar nos efeitos das suas ações. A banalidade do mal produz esse tipo de subjetividade, distanciada da própria realidade da qual é criação e ponto material de reprodução do mal. Esse distanciamento, um certo desinteresse, é que constitui o modo como a maldade pode fazer parte de um cotidiano, de uma vida comum, de pessoas comuns. 0 intrigante é supor que as pessoas sejam capazes de realizar qualquer ato de destruição e morte sem que isso se sustente em motivação maligna, mas como parte inexorável do seu cotidiano.

0 banal, paradoxalmente, é assustador. Sua marca mais significativa é a negação do pensamento. Ele sequer supõe que seja possível pensar. Ao contrário, desdenha do pensamento, da pesquisa, das ciências e até mesmo das razões ou dos argumentos. Qualquer coisa que implique uma atividade conceitual, sob o pano de fundo do senso comum, se torna um ataque à opinião que, no interior do dispositivo, adquire caráter de conhecimento absoluto. Assim como o mal pôde ser banalizado a tal ponto que uma pessoa comum pudesse conviver com campos de concentração e extermínio em massa, qualquer campo da vida pode igualmente ser atormentado pela banalidade.

Decerto que o que se desenha no mundo e na sociedade brasileira é a composição de um dispositivo de poder que impõe um novo estatuto à opinião comum, levada ao extremo da banalização de afirmações e concepções deslocadas em relação a qualquer forma de pesquisa científica, metodologia de análise ou mesmo do uso de evidências e de base empírica. 0 banal torna-se a "medida de todas as coisas" e é a partir dele que o juízo se produz. Trata-se de um dispositivo que produz saberes que se tornam cristalizados e que estabelecem um vivo e pulsante paradoxo ao qual somos submetidos: a opinião se converte em um direito diante de quaisquer outras formas de conhecimento ou saberes sob o argumento da liberdade de expressão. Ao mesmo tempo, num passe de mágica, essa mesma opinião que se insere no campo aberto e plural da liberdade de expressão se transforma em verdade, consenso, senso comum, obviedade e, portanto, irreparável e livre de oposição ou crítica. 
Eis o que se pode ver e dizer a partir de um dispositivo da banalidade. Através de uma série de pontos materiais, formas de dizer e de ver constituem esse dispositivo, construindo um diagrama que produz linhas, criando comportamentos, modos de ser, enunciados, imaginários e uma quantidade significativa de subjetividades que pronunciam e enunciam um conjunto articulado de clichês sobre os mais variados temas da vida humana. Um dispositivo, na leitura de Foucault (1988), é uma rede que inclui elementos discursivos e não discursivos, enunciados, instituições, imagens, regulamentos morais, proposições científicas, políticas ou leis. Um dispositivo encerra, portanto, um limite do ver e do falar. Agamben (2005), em conferência que analisa o conceito de dispositivo em Michel Foucault, afirma que os "dispositivos são precisamente o que na estratégia foucaultiana ocupa o lugar dos Universais: não simplesmente esta ou aquela medida de segurança, esta ou aquela tecnologia do poder, e nem mesmo uma maioria obtida por abstração: de preferência, como dizia na entrevista de 1977, 'a rede (le réseau) que se estabelece entre estes elementos". A ideia de rede implica supor que o dispositivo apresenta um conjunto de modelos, de modos de fazer ou de ser, produzindo padrões e normas que regulam o funcionamento de uma sociedade.

No caso em questão, o dispositivo de banalidade constitui um movimento bastante conhecido, que faz calar a linguagem e qualquer processo criativo em nome da arrogância dos clichês. Disponíveis a partir do dispositivo da banalidade, os clichês se tornam uma tagarelice que não cessa de, paradoxalmente, calar e apagar a complexidade das coisas em troca da opinião banal - inclua-se aí uma série bastante significativa de práticas sociais e imaginários que transitam pela violência física e simbólica até o cerceamento (a censura) da criação conceitual e do pensamento. 0 ensino de história tem convivido com esse padrão de normalidade do banal, pois é nesse espaço em que as opiniões parecem querer se sobrepor ao conhecimento e aos saberes que procuramos produzir a crítica e a interpretação do tempo e das temporalidades. A desvalorização da aula de história e da própria narrativa histórica habita desde os altos escalões das instituições governamentais, passando por movimentos que questionam o conhecimento e os conceitos produzidos e com os quais se operam as análises históricas, até a difusão de opiniões que passam a fazer parte do cotidiano da aula de história.

0 desdém pelo conhecimento acadêmico e científico, fundado na crítica à vida universitária, por meio de um discurso fácil e banal de um suposto complô comunista, parece ser uma ideia-força que eleva o elemento da opinião em detrimento da complexidade e do pensamento. É importante lembrar que, em diversos momentos históricos nos quais a solução foi o fascismo ou as ditaduras, o inimigo comum construído foi justamente o suposto comunismo. Nos mais diversos casos, trata-se de um inimigo imaginário, feito inclusive sem base na realidade empírica e nas forças políticas em jogo em cada momento, nem nas interpretações históricas disponíveis.

A sala de aula de história pode ser um território sensível ao dispositivo de banalidade, mas, outras vezes, faz aparecer abismos que permitem a criação de linhas de fuga, que deixam desfilar acontecimentos e provocam a desacomodação e o desvio em relação à banalidade. Logo, a sala de aula, que acolhe e escuta os saberes diversos, das juventudes, dos povos, das comunidades, dos movimentos sociais e os coloca em diálogo com os 
conceitos históricos, é um dos poucos lugares onde a complexidade resiste e pode ter efeitos sobre a vida dos jovens e seus modos de criar novos mundos. Eis a razão pela qual o pensamento é conceito central deste artigo. Pensar é uma maneira que a aula de história possui para fazer-se espaço de criação e, portanto, de fuga em relação ao dispositivo.

Acreditamos que conviver com o que estamos chamando de dispositivo de banalidade implica certa aprendizagem, que compreende tanto o elemento da reação aos clichês (que têm informado sobre o que é verdadeiro e aceitável) num tempo de opinião, quanto o elemento da criação que, numa exterioridade em relação ao próprio dispositivo, pode ampliar as expectativas de futuro dos estudantes, oferecendo imaginação e valores éticos e estéticos

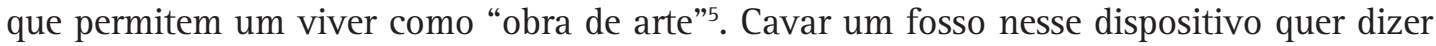
também criar modos diversos de viver e de ter experiência. Logo, são necessárias a violência do pensamento e a provocação do acontecimento em sala de aula.

\section{O pensar e seus paradoxos}

Para Hannah Arendt, a ausência de pensamento (fenômeno que ela identificou em Eichmann) não é sinônimo de ausência de conhecimento formal, tampouco significa o esquecimento do que se aprendeu ao longo da vida, das regras de civilidade. Em "A vida do espírito", publicado parcialmente pela primeira vez em 1971, a pensadora parte de suas constatações sobre a banalidade do mal e do abuso de clichês que protegem da realidade, mas impedem, ao mesmo tempo, a criação do novo. Nesse sentido, a hipótese de Arendt, em sua última e inacabada obra é:

[...] seria possível que a atividade do pensamento como tal - o hábito de examinar o que quer que aconteça ou chame a atenção, independentemente de resultados e conteúdo específico - estivesse entre as condições que levam os homens a abster-se de fazer o mal, ou mesmo que ela realmente os "condicione" contra ele? (ARENDT, 2008, p. 20).

Uma primeira reflexão sobre o pensar tem a ver com sua autonomia relativa diante do mundo sensível. Para Arendt, pensar e conhecer são atividades distintas. Não há implicação direta entre obter e produzir conhecimento científico e não fazer o mal, ou seja: pessoas muito bem treinadas em suas áreas de pesquisa podem, paradoxalmente, ser incapazes de pensar, já que a cognição encaminha para o encontro com verdades, mas somente o pensar busca os significados, sempre provisórios e passíveis de novas contradições. Entretanto, a autonomia do pensar diante do mundo sensivel é apenas relativa devido a dois aspectos principais. 0 primeiro é que a existência humana é mundana, isto é, somos porque aparecemos no mundo para os demais e constituímos nossas identidades em função dos outros. A atividade de pensar, nessa primeira análise, consiste num afastamento provisório do mundo dos sentidos. Porém, a produção de significados demanda sua comunicação com os outros, o que se faz por meio de metáforas, já que é impossivel expressar exatamente o que pensamos e como pensamos.

5- A referência que fazemos à vida como "obra de arte" é de Agamben (2005). 
Nesse sentido, é por meio do pensamento que escolhemos as formas como queremos que as pessoas nos vejam. Isso significa, por outro lado, que o pensar também está passível de limites, ou melhor, do que Arendt chama de "semblância": as coisas parecem verdadeiras devido aos limites do lugar que o ser pensante ocupa (2008, p. 55). A manipulação de semblâncias pode levar a ilusões, isto é, a fazer com que os outros acreditem ser verdade algo que apenas aparenta ser. Desvelar uma ilusão é válido, mas esse movimento não necessariamente revela a verdade única, a aparência imutável, o autêntico. Daí se conclui que a atividade de pensar tampouco garante seguranças irrefutáveis que poderiam orientar a vontade e a ação.

Para Arendt, o ser pensante não é a causa nem o fundamento dos pensamentos, pois ele é pura atividade e experiência, um movimento que não se baseia em relações de causa-consequência com o mundo sensível. Trata-se muito mais da "[...] condição de um ser vivo que, ainda que parta do mundo das aparências, tem uma faculdade - a habilidade de pensar, que permite ao espírito retirar-se do mundo, sem jamais poder deixá-lo ou transcendê-lo" (ARENDT, 2008, p. 62) e é essa condição de partilha com o senso comum que impede que o pensar seja identificado como atividade exclusiva de sujeitos especiais, que possuiriam habilidades acima dos outros. A suspensão do mundo sensível é, portanto, apenas aparente, sendo mais próxima do lapso ou do invisível, como no exemplo das raízes das plantas: não precisamos vê-las para saber que estão ali.

É nessa tensão entre o visível e o invisível que a autora caracteriza o pensar em torno de evocações daquilo que não está visível, pelo conceito ou pela imaginação, rearranjando e recriando livremente o que não está - momentaneamente - dominado pelas regras do tangível, inclusive a memória e as projeções de futuro. Para sintetizar o paradoxo: "[...] todo pensamento deriva da experiência, mas nenhuma experiência produz significado ou mesmo coerência sem passar pelas operações de imaginação e pensamento" (ARENDT, 2008, p. 106). Nesse ciclo, o pensamento pode destruir inclusive a si próprio a fim de seguir pensando. Não há ponto de chegada eterno e incontestável, e talvez derive daí, como mencionamos antes, a inefabilidade do pensar, que se expressa, mal ou bem, por metáforas. Para a autora, a metáfora mais adequada para o pensar é a da vida, como movimento circular de busca de significado - tal como os deuses gregos, que eram pura energia e atividade.

0 que nos motiva a pensar - afırma Arendt baseada em Sócrates - é o espanto em relação ao que nos é próximo e conhecido, algo parecido com o estranhamento, que leva à sensação de vertigem e assombro. 0 pensamento desnaturaliza, afasta o torpor e convida a compartilhar sentidos.

É da natureza deste elemento invisível desfazer e, por assim dizer, degelar o que a linguagem, o veículo do pensamento, congelou como pensamentos-palavras (conceitos, frases, definições, doutrinas), cuja "impotência" e inflexibilidade Platão tão brilhantemente denuncia na Sétima carta. A consequência é que o pensamento tem inevitavelmente um efeito destrutivo e corrosivo sobre todos os critérios estabelecidos, valores, padrões para o bem e para o mal, em suma, sobre todos os costumes e regras de conduta com que lidamos em moral e ética. Estes pensamentos congelados, Sócrates parece dizer, ocorrem tão facilmente que até dormindo podemos fazer uso 
deles; mas se o vento do pensamento que agora provoquei sacudiu você do seu sono e deixou-o totalmente desperto e vivo, você verá que pode dispor apenas de perplexidades, e o melhor que se pode fazer com elas é partilhá-las com os outros. Assim, a paralisia induzida pelo pensamento é dupla: ela é inerente ao parar para pensar, à interrupção de todas as atividades [...] e pode ser também um efeito atordoante, depois que a deixamos, nos sentindo inseguros sobre o que parecia acima de qualquer dúvida enquanto estávamos impensadamente engajados em fazer alguma coisa (ARENDT, 2008, p. 197, grifos no original).

Portanto, parar para pensar não garante a aplicação imediata de regras de conduta preestabelecidas. Para se aproximar ainda mais de seu problema central, isto é, a atividade de pensar como antídoto para a banalidade do mal, Arendt explora os lugares e tempos do pensar. Primeiramente, ela estabelece (com Platão e Sócrates) que a atividade de pensar consiste num diálogo de cada um consigo próprio, em que a coerência interna, a amistosidade com seu próprio ser, parece ser uma pista para as tomadas de decisão de cunho ético e moral. Na esteira de Kant e Espinosa, a pensadora defende que a ausência de pensamento não torna automaticamente alguém bom ou mau, nem mais ou menos inteligente: essa pessoa apenas não se coloca à prova do encontro consigo mesma ${ }^{6}$. E se o pensar é como o movimento da vida, recusar-se a pensar é como recusar-se a viver. Os efeitos morais do pensamento são, portanto, apenas tangenciais e só seriam ativados naquilo que ela chama, apoiada em Jaspers, de "situações-limite", isto é, quando nos damos conta da contingência e buscamos alargar os limites de tempo e espaço imediatos, o que tem uma consequência política.

Quando todos estão deixando-se levar, impensadamente, pelo que os outros fazem e por aquilo em que creem, aqueles que pensam são forçados a mostrar-se, pois a sua recusa em aderir torna-se patente, e torna-se, portanto, um tipo de ação. Em tais emergências, resulta que o componente depurador do pensamento [...] é necessariamente político. Pois essa destruição tem um efeito liberador sobre outra faculdade, a faculdade do juízo, que podemos chamar com alguma propriedade de a mais política das capacidades espirituais humanas. [...] A manifestação do vento do pensamento não é o conhecimento, é a habilidade de distinguir o certo do errado, o belo do feio. $\mathrm{E}$ isso, nos raros momentos em que as cartas estão postas sobre a mesa, pode sem dúvida prevenir catástrofes, ao menos para o eu. (ARENDT, 2008, p. 214).

Pensamento não tem hora nem lugar, interrompe e é interrompido. Pensamento é caos movendo-se entre o que já não é mais e o que ainda não veio, isto é, o agora. 0 agora é o ponto de partida, quiçá mobilizador, mas o sentido do pensamento não é determinado pelo passado, muito menos influenciador do futuro, pois está sempre num espaço "entre", em que podemos destruir certezas, refazer perguntas e criar sempre novas respostas. E, em tempos de urgência, o vento livre do pensamento pode "prevenir catástrofes".

0 que aprendermos sobre banalização e sobre pensamento são forças muito significativas para refletir sobre o que ocorre hoje no Brasil - e no ensino de História -,

6- Essa explicação de Hannah Arendt lembra a personalidade de Scarlett O'Hara, que, quando acuada pelas contradições de suas escolhas, repelia o encontro consigo mesma para mergulhar no pensamento: "[... . Não quero pensar nisso agora [... . . Eu enlouqueço se pensar que o perdi. Amanhã pensarei no assunto" (MITCHELL, s.d., p. 960). 
pois uma sociedade fascista não se constrói da noite para o dia. São pequenos movimentos e medidas que preparam o terreno para criar, senão um Estado Fascista e autoritário, uma sociedade que não pensa e que banaliza tudo, inclusive o mal, como já mencionamos no início. Não ignoramos que todos esses movimentos possuem conexões importantes, mas nos interessa aqui refletir sobre a responsabilidade do ensino de história em um tempo que nos parece eivado de "situações-limite", em que os ventos que sopram do paraíso exigem revolução, pois os escombros das catástrofes criadas pela modernidade capitalista não pararam de se acumular diante dos nossos pés (BENJAMIN, 1987). Talvez seja tempo de escovar o ensino de história a contrapelo, e não só a história.

Em momentos de urgência, a relação temporal, o arejamento do tempo - que é também o arejamento da utopia (JACOBY, 2007) - pode ter maior implicação na vida prática, na tomada de decisão. A ideia de que saber história ajuda a tomar decisões éticas, a não fazer o mal para os outros, tampouco pode ser banalizada, embora seja muito frequente na literatura da área, em diversos lugares. Veronica Boix-Mansilla (2000), por exemplo, orientou suas pesquisas pela premissa de que jovens que desenvolvem pensamento histórico comparado, trabalhando com temas ligados aos direitos humanos, podem ter relações mais empáticas com os demais e, quiçá, lutar por mais justiça social no mundo.

De forma semelhante, Joan Pagès (2015) defende, ao longo de toda a sua obra e nos trabalhos do Grupo de Pesquisa em Didática das Ciências Sociais (Gredics, na sigla em catalão, da Universidade Autônoma de Barcelona), a relevância de construir aulas e currículos que partam de questões práticas do tempo presente, proporcionem estudos conceituais e retornem com propostas de intervenções diretas na vida cotidiana. 0 trabalho de Pagès e de seus parceiros tensionam a produção na didática da história europeia que procura, em geral, manter-se distante das polêmicas contemporâneas, embora a legislação educacional do velho continente, nos últimos 25 anos, procure implicar a escola e a democracia.

En todos los casos se pide a la escuela una actitud militante en la construcción de una conciencia cívica democrática que permita avanzar hacia una sociedad y hacia un mundo más justo y más igualitario. Se considera que la democracia no es un estado final, sino um proceso inacabable que implica vivencia, conocimiento y compromiso. (PAGĖS, 2015, p. 19).

A formação para a cidadania participativa, crítica e transformadora, de inspiração freireana e deweyana, recebe foco central desse autor, cuja obra tem sido cada vez mais influente na América Latina, inclusive no Brasil (JARA; SANTISTEBAN, 2018). 0 tema das Questões Socialmente Vivas (QSV) ou Problemas Socialmente Relevantes (PSR) exemplifica esse diálogo entre o ensino de História e as urgências do tempo presente. 0 manual de Yannick Mével e Nicole Tutiaux-Guillon (2013) dedica um capítulo às ditas QSV, demonstrando sua inserção no currículo de histoire-géographie francês e as polêmicas das leis memorialistas. As discussões oferecidas pelos autores demonstram, porém, que as QSV são quase independentes dos discursos oficiais, tendo em vista que nascem, em grande medida, da participação dos próprios estudantes em sala de aula. Na América Latina, o dossiê organizado por Juliana Alves de Andrade, Carmem Zeli de Vargas Gil e Juliana Pirola Balestra apresenta a força desse debate. 


\begin{abstract}
A história no espaço escolar evitou temas delicados, controversos e sensíveis, porque envolve a violação de direitos e pode revelar as disparidades entre o que é assumido como memória pública e o que se discute internamente nos espaços de sociabilidade. Em alguns casos, tem receio de tomar partido em questões políticas e em lidar com processos inacabados que envolvem pessoas vivas e ativas na arena política e social. No entanto, o contexto atual tem desafiado a escola e o componente curricular de história a se posicionar diante das desigualdades e injustiças sociais vivenciadas pelas crianças, jovens ou seus familiares. E de certo modo, o ensino de história tem se tornado um lugar de resistência ao enfrentar o desafio de educar para a defesa dos direitos humanos. 0 papel do ensino de história é ensinar a conviver com a diversidade e a se posicionar no mundo. (ANDRADE et al., 2018, p. 4-5).
\end{abstract}

No Brasil, é possível identificar desde os anos de 1980 (certamente também antes) a interlocução entre a construção da democracia, o ensino de história e a constituição das identidades docentes. Um exemplo é o artigo de Déa Ribeiro Fenelon (1982, p. 7), que inicia com questões como esta: "de que realidade estamos falando quando dizemos que a história é importante porque nos ensina a analisar a realidade para podermos transformá-la?”. Parece haver certa tradição, no campo do ensino de história, em vincular as razões e as metodologias da área a uma noção - mais ou menos difusa - de que é preciso intervir no mundo, pelo conhecimento histórico, para torná-lo melhor.

Entretanto, pesquisas qualitativas preocupadas com o pensamento de professores de história demonstraram que essa conexão não é imediata, nem utilitarista. Não se trata de filiação a partidos políticos, tampouco a movimentos sociais específicos (embora isso possa estar presente): religião, trajetória familiar, referenciais teóricos, experiências profissionais, exemplos de professores parecem ser mais relevantes para os professores de história quando são convidados a explicar suas utopias identificadas como políticas e educacionais ao mesmo tempo. Em seus testemunhos, evidenciam-se dois aspectos que escapam ao discurso acadêmico: o primeiro é a referência concreta aos estudantes, seus mundos, anseios, culturas, forças e fragilidades; o segundo - que deriva do primeiro - é a prudência, isto é, uma abordagem cuidadosa e respeitosa diante das vidas dos estudantes em relação aos objetivos emancipadores do ensino de história (PACIEVITCH, 2016). 0 que se nota é que, por mais que a tradição acadêmica da área enfatize certo ativismo, os professores que participaram dessas pesquisas filtram essas exigências diante dos olhares de seus estudantes e desconfiam, com razão, da afırmativa (banal?) de que quem estuda história tem, automaticamente, pensamento crítico e compromisso com um futuro mais justo para todos. Tal desconfiança, porém, não significa que desdenham completamente da premissa. Voltamos ao paradoxo do pensamento e das escolhas éticas.

\title{
As linhas de criação em uma aula de história: resistência aos dispositivos
}

0 que se reserva para a aula de história, pensamos, é uma delicada operação que provoca o pensar, violenta os padrões e os modelos a partir do dispositivo de banalidade e, desse modo, oferece a dúvida e a curiosidade como elementos constitutivos de um espírito hipercrítico (VEIGA-NETO, 1995). Nesse sentido, o esquecimento é um aliado importante, 
ele faz com que a aula de história seja menos reativa e mais criativa. Para demonstrar uma aula que esquece momentaneamente as injunções que dificultam o pensamento, separamos uma experiência que reproduzimos a seguir.

0 professor fechou lentamente a porta de sua sala de aula. Ali, um esquecimento das identidades que o dispositivo de banalização faz imprimir em cada um de nós, professores de história, tornou possível uma aprendizagem conceitual, movida pela curiosidade, pela imaginação e pela exterioridade. A ideia era provocar efeitos sobre os imaginários que produzimos sobre o passado, sobre os povos e sobre as temporalidades. Vinicius Bondarenco Beulk ${ }^{7}$ se apressou em apresentar, sem fazer qualquer referência ao conteúdo da aula, dois videoclipes de um artista já falecido, Michael Jackson, e de uma artista atual, Katy Perry. Cada um deles fazia referência a uma mesma temporalidade, a um mesmo povo e a um mesmo território: o Egito Antigo. 0 primeiro era da música "Remember the time", e o segundo, da música "Dark Horse".

Os estudantes ficaram empolgados com uma aula de história que se iniciava, imediatamente, com dois ícones do pop estadunidense e internacional. Na leitura deles, seria absolutamente improvável que uma aula de história, no ano de 2019, pudesse fazer habitar ali o rei do pop, Michael Jackson, e a não menos festejada por milhares de jovens no mundo inteiro, Katy Perry. A curiosidade pode ter sido parte daquilo tudo, mas a vontade de ver os vídeos e escutar as músicas - muitas cantaram junto com Katy Perry - foi muito mais instigante. Os dois vídeos parecem ter afastado do ambiente todo um presente cheio de questões, enredos e lutas políticas que, naquele momento, ficaram fora da sala de aula, afınal, nestes tempos de "urgência", em que vivemos, reafirmamos que "o vento livre do pensamento pode "prevenir catástrofes”. Tanto que, certamente, ali não houve qualquer tentativa de gravar a aula e enviar para o Ministério da Educação, como forma de denunciar um professor de história que estivesse a ensinar sobre o malfadado Marxismo Cultural, obsessão do dispositivo de banalidade.

0 objetivo do professor Vinicius era muito mais alto do que os próprios estudantes estavam a supor: entravam naquela aula, sorrateiramente, os usos do passado, os imaginários que criamos sobre os outros, o conceito de representação, o racismo estrutural, o Egito imaginado e, por fim, um Egito histórico, resultado da produção historiográfica e narrativa. Tudo isso no interior de uma única aula de 50 minutos, com a utilização de dois videoclipes. E foi assim que o pensamento se instalou, no exato instante em que a desatenção à vida, a inatividade oferecida pela música foi o mesmo que se inserir num "entre", numa cesura temporal e que o elemento do sonho se sobrepôs à eterna vigília do presente, que os vídeos e a fala provocativa do professor produziram o fosso necessário à fuga em relação às marcas, aos modelos, aos estereótipos, aos clichês que o dispositivo fez circular pelo cotidiano daqueles jovens. Foi no fundo desse fosso (no "entre" do pensamento, na inatividade da música) que o clipe de Katy Perry preencheu o imaginário de um Egito branco e não africano, pois os personagens que representavam os egípcios eram todos brancos ou azuis. A atenção se voltou para o problema, inserido pela provocação do professor, quando, ao final do vídeo de Michael Jackson, foi possível constatar que ali os personagens eram negros. 0 mergulho numa criação imaginária que o presente faz sobre o passado levou a uma

7- Vinicius Bondarenco Beulk é estudante de Licenciatura em História, do semestre 2019/02, da UFRGS, estagiário do Ensino Médio na escola Instituto de Educação, em Porto Alegre. 
profunda violência ao que os estudantes estavam acostumados a ver sobre si mesmos e sobre os africanos. Decorreu, daí, uma intensa batalha entre os modos como temos criado imagens sobre o passado, o modo como cristalizamos representações sobre a África e, sobretudo, a maneira como o racismo estrutura nossos modos de ser, olhar e nos relacionar. Teria sido igualmente problematizador inserir, ainda, uma imagem de Elizabeth Taylor no papel de Cleópatra, num filme de 1963, dirigido por Joseph L. Mankiewicz, produzindo efeitos sobre como os egípcios foram, por anos, imaginados pelo mundo ocidental. Isso significa que construímos, através da música e, neste caso, do cinema, da televisão e, inclusive, da escola, um imaginário sobre o Egito Antigo. E o elemento central desse imaginário é um Egito não africano, um Egito não negro. Ao sinal de término daquela aula, o professor apresentou autores africanos e se iniciou uma etapa de acúmulo de erudição sobre um Egito africano, negro.

Num jogo complexo entre os acontecimentos do interior da sala de aula e as urgências que limitam a liberdade de pensar, se insinuando para impedir a criação, foi o elemento criativo e acontecimental das relações nada banais entre conceitos históricos, culturas juvenis, imaginários e usos do passado que se fizeram saltar para fora do dispositivo, produzindo um lugar ao pensamento.

Ora, sabemos bem que é responsabilidade docente responder às demandas do tempo presente e reagir à banalidade do mal. Talvez o que aprendemos é que o tradicional compromisso do ensino de História com a transformação do mundo ganha fôlego se olharmos para a lição trazida por Arendt, que repousa num paradoxo: o pensamento combate o mal justamente por sua capacidade de implodir o imediato e permitir a imaginação e a criação do novo, sem jamais deixar de lado a comunicação com os outros, pois é dela que emergem os novos sentidos. Talvez o momento no qual vivemos seja uma boa hora para viver esse paradoxo, deixando que as respostas ao dispositivo sejam conduzidas pela problematização das memórias que ele produz e que alguma inatividade e desinteresse em relação ao presente possam situar nossas aulas numa exterioridade que as torne espaço abrigado e refugiado de um certo reativismo. É o espaço que precisamos para pensar.

Por um lado, a preocupação com as crueldades cometidas na história nos conduz à crítica produzida por White, quando nos lembra que nossa “vangloriada 'civilização' deve seus méritos e benefícios aos tipos peculiares de crueldade cometidos pelos humanos contra sua própria espécie” (2019, p. 12), como se a própria ideia de civilização - que por muito tempo a narrativa histórica nos levou a festejar - fosse construída sobre estruturas do mal e que tais estruturas, às vezes arquitetônicas, às vezes simbólicas, parecem fazer parte de um cotidiano que as desconhece ou que as banaliza. E, nos braços da ingenuidade ou da banalização que dispensam o pensamento, somos sugados para um dever de esquecimento tão radical que nos torna familiares ao mal, a toda "crueldade cometida pelos humanos contra sua própria espécie" (WHITE, 2019, p. 12).

Por outro lado, a aula de história, a partir de outra forma de esquecimento, do fulgor de uma provocação, na inatividade de uma música ou na beleza pouco recatada da criação e do pensamento, nos induz a uma passividade insuspeitada, forjada por fragmentos de um tempo que, provocativo e problematizador, se oferece como fonte e violência que levam a pensar, sendo este pensar, antes de reagir, um modo de criar mundos novos, futuros 
imprevisíveis. Como nos mostrou a aula que se utilizou dos videoclipes de Michael Jackson e Katy Perry, o pensamento se instala a partir dessa exterioridade em relação ao imediato, o que permite deslocar-se de um presente que exige atenção constante. Isso não quer dizer que essa inatividade e desatenção não sejam as armas necessárias para problematizar de modo mais sofisticado nosso próprio mundo. A aula sobre o Egito nos surpreende pela capacidade de problematização das imagens que criamos sobre o passado, sobre os povos, sobre os outros; nos incentiva a pensar sobre como usamos as imagens e as histórias que escrevemos sobre nossos irmãos humanos e como essas imagens e escritos são definidores, formadores e, sobretudo, cerceadores e silenciadores. Ao definirem, no âmbito da memória e da história, o que é o outro (como o Egito seria branco e não africano), impedem as novas gerações de jogar com o caos da natureza e com o movimento do real. Cada ponto de parada criado pela imagem de uma rainha egípcia no corpo de uma atriz branca, cada reconstrução, no contexto de um videoclipe, de um Egito onde pessoas brancas habitam, governam ou se relacionam usurpa o excesso que se chama Egito, retira a qualidade da diversidade, da pluralidade e da multiplicidade. A aula de História, então, produz pontos de parada, elabora explicações, cria narrativas que reduzem ao propor conceitos e estabelecer limites temporais. Mas uma aula de história faz muito mais do que isso, ela se oferece como espaço desse excesso que é o Egito Antigo e que, como excesso, permite o jogo da criação narrativa a partir de um lugar exterior que provoca o pensamento e leva à dúvida em relação aos pontos de parada já criados (imaginários e histórias escritas). E isso tudo implica um modo muito sofisticado de combater, sem simplesmente reagir, o dispositivo de banalidade, bem como a banalidade do mal.

\section{Referências}

AGAMBEN, Giorgio. 0 que é um dispositivo? Revista Outra Travessia, Ilha de Santa Catarina, n. 5, 2005. Disponível em: https://periodicos.ufsc.br/index.php/Outra/article/view/12576. Acesso em: 06. fev. 2019.

ANDRADE, Juliana Alves de; GIL, Carmem Zeli de Vargas; BALESTRA, Juliana Pirola da Conceição. Ensino de história, direitos humanos e temas sensíveis. História Hoje, São Paulo, v. 7, n. 13, p. 4-13, 2018. Disponível em: https://rhhj.anpuh.org/RHHJ/article/view/458/257. Acesso em: 20 jun. 2019.

ARENDT, Hannah. A vida do espírito: o pensar, o querer e o julgar. Rio de Janeiro: Civilização Brasileira, 2008.

ARENDT, Hannah. Eichmman em Jerusalém: um relato sobre a banalidade do mal. Tradução José Rubens Siqueira. São Paulo: Companhia das Letras, 1999.

BAUMAN, Zigmunt. Modernidade e Holocausto. Tradução de Marcus Penchel. Rio de Janeiro: Jorge Zahar, 1998.

BENJAMIN, Walter. Obras escolhidas I. São Paulo: Brasiliense, 1987.

BOIX-MANSILLA, Veronica. Historical understanding: beyond the past and into the present. In: STEARNS, Peter; SEIXAS, Peter; WINEBURG, Sam (org.). Knowing, teaching and learning history: national and international perspectives. New York: New York University Press, 2000. p. 326-350. 
CABRINI, Conceição et al. Ensino de história: revisão urgente. São Paulo: Paz e Terra, 1986.

FENELON, Déa Ribeiro. A formação do profissional de história e a realidade do ensino. Projeto História, São Paulo, n. 2, p. 7-19, 1982. Disponível em: https://revistas.pucsp.br/index.php/revph/article/ download/12423/9004. Acesso em: 25 jun. 2019.

FOUCAULT, Michel. Microfísica do poder. Rio de Janeiro: Graal, 1988.

JACOBY, Russel. Imagem imperfeita. Pensamento utópico para uma época antiutópica. Rio de Janeiro: Civilização Brasileira, 2007.

JARA, Miguel Ángel; SANTISTEBAN, Antoni (org.). Contribuciones de Joan Pagès al desarrollo de la didáctica de las ciencias sociales, la historia y la geografia en Iberoamérica. Cipolletti: Universidad Nacional del Comáhue; Universidad Autónoma de Barcelona, 2018.

MEINERZ, Carla Beatriz.; GASPAROTTO, Alessandra. Apresentação - "Da pequena para a grande roda": encontro de saberes e poderes no ensino de história. ENCONTRO NACIONAL PERSPECTIVAS DO ENSINO DE HISTÓRIA E JORNADA DE ENSINO DE HISTÓRIA E EDUCAÇÃO, 10., 23, Porto Alegre). 16-18 jul. 2018. Anais... Disponivel em: https://www.ufrgs.br/lhiste/anais-perspectivas-do-ensino-de-historia/. Acesso em: 20 jun. 2019. p. 23-27.

MÉVEL, Yannick; TUTIAUX-GUILLON, Nicole. Didactique et enseignement de l'histoire-géographie au collège eu au lycée. Paris: Publibook, 2013.

MILMAN, Luis; VIZENTINI, Paulo Fagundes (org.). Neonazismo, negacionismo e extremismo político. Porto Alegre: UFRGS; Corag, 2000.

MITCHELL, Margaret. ...E o vento levou. São Paulo: Círculo do Livro, s.d.

MOURA, Carla de. As Marias da Conceição: por um ensino de história situado, decolonial e interseccional. 2018. Dissertação de (Mestrado em Ensino de História). - Universidade Federal do Rio Grande do Sul, Porto Alegre, 2018.

NIETZSCHE, Friedrich. 0 nascimento da tragédia, ou Helenismo e pessimismo. Tradução J. Guinsburg. São Paulo: Companhia das Letras, 1992.

PACIEVITCH, Caroline. Utopias político-educacionais na formação de professores de históriageografia: possibilidades de uma abordagem comparada, Porto Alegre: [s. n.], 2016. mimeo.

PAGÈS, Joan. La educación política y la enseñanza de la actualidad en una sociedad democrática. Educação em Foco, Belo Horizonte, v. 19, n, 3, p. 17-37, nov. 2014/fev. 2015. Disponível em: https://goo.gl/CCrcNv. Acesso em: 24 fev. 2019.

RICOUER, Paul. Tempo e narrativa 2. Tradução Márcia Valéria Martinez de Aguiar. São Paulo: Martins Fontes, 2010. 
VEIGA-NETO, Alfredo. É preciso ir aos porões. Revista Brasileira de Educação, São Paulo, v. 17, n. 50, maio/ago, 2012. p. 267-282.

WHITE, Hayden. 0 passado prático. Tradução Arthur Lima de Avila, Mario Marcello Neto, Felipe Radünz Krüger. ArtCultura, Uberlândia, v. 20, n. 37, p. 9-19, jul./dez. 2018.

Recebido em: 14.07.2019.

Aprovado em: 18.02.2020.

Caroline Pacievitch é professora da Faculdade de Educação da Universidade Federal do Rio Grande do Sul.

Nilton Mullet Pereira é professor da Faculdade de Educação da Universidade Federal do Rio Grande do Sul. 